\title{
A Case Based Study on the Implementation of National Health Schemes on Treatment Techniques of Lung Cancer
}

\author{
Mrinal Deka', Dibyojyoti Bhattacharjee ${ }^{2}$ and Avijit Debnath ${ }^{3}$ \\ ${ }^{1} P h . D$. Research Scholar, Department of Statistics, Assam University, Silchar, India, PIN: 788011, \\ ${ }^{2}$ Professor, Department of Statistics, Assam University, Silchar, India, PIN: 788011 \\ ${ }^{3}$ Assistant Professor, Department of Economics, Assam University, Silchar, India, PIN: 788011, \\ Assam University, Silchar
}

\section{ABSTRACT}

Looking at the global scenario and studying the health diseases related spatial data, it has been observed that the incidence of cancer is a matter of serious public health concern as compared to others. Since the treatment patterns of cancer and consequent impacts on the households are different, it is necessary to understand the major types of conventional treatments/procedures undertaken from time to time. This in turn is expected to provide information and choice to the patient families before undertaking any decision regarding treatment conditional upon availabilities and their abilities. The study has policy implications in the sense that it is expected to help optimal policy designs for the cancer patients in long run. The present study is first of its kind for patients in Assam and focused on the effect of only two available health schemes viz. Pradhan Mantri Jan Arogya Yojana (PM-JAY) and Atal Amrit Abhiyan (AAA) on treatment of lung cancer. The results show that both the schemes have successfully implemented on the lung cancer patients in Assam as the probability of completion of treatment is 76.6 percent higher if the patients treated through these two schemes as compared to not using these schemes.

KEY WORDS: NATIONAL HEALTH SCHEMES, TREATMENT TECHNIQUES, CANCER, POLICY DESIGN, PUBLIC HEALTH.

\section{INTRODUCTION}

Cancer is emerging as a major public health concern in India and other parts of the world due to ongoing demographic and epidemiological transition (Rajpal. et.al, 2018 and Jemal.et.al, 2010). It is a general term used for a group of diseases and develops from the

\section{ARTICLE INFORMATION}

Received 4th Oct 2020 Accepted after revision 9th Dec 2020 Print ISSN: 0974-6455 Online ISSN: 2321-4007 CODEN: BBRCBA

Thomson Reuters ISI Web of Science Clarivate Analytics USA and Crossref Indexed Journal

\section{Clarivate
Analytics}

NAAS Journal Score 2020 (4.31)

A Society of Science and Nature Publication,

Bhopal India 2020. All rights reserved.

Online Contents Available at: http//www.bbrc.in/

Doi: $h t t p: / / d x$.doi.org/10.21786/bbrc/13.15/2 extra mass tissue known as tumour (Baghestani.et.al, 2015). However, limited study has been undertaken to understand the heterogeneity and impacts of various types cancer separately.

The growing incidence of lung cancer cases are matter of serious burden in the society and considered as common occurring cancer in men and the third most common occurring cancer in women (Aggarwal.et.al, 2016). It is observed that the biggest risk factor for lung cancer is smoking (Aggarwal.et.al, 2016). Each year about 7,300 people who never smoked die from lung cancer caused by passive smoke in the United States (Fernandez.et.al,2014). The risk of developing lung cancer is still high for former smokers, however, quitting smoking can significantly lower that risk. The risk of dying from lung cancer may be dropped by half within 10 years of quitting (Fernandez.

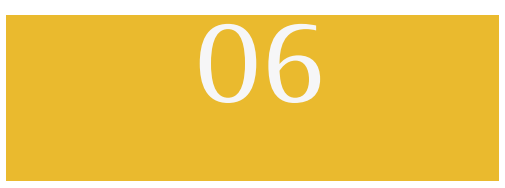


et.al, 2014). Early symptoms of lung cancer may include lingering or worsening cough, coughing with blood, chest pain that worsens when breathe deeply, laugh or cough, hoarseness, shortness of breath, wheezing, weakness and fatigue, loss of appetite and weight loss.

Talking about the treatment process, one might know about different types of therapies available in the market. The patients are not often informed about the cause, nature and cost of such therapies. Similarly, patients mostly do not have any information on the different treatment techniques/set of processes and tools and their implications. As an example, Radiation therapy (often called ionizing radiation therapy (Baskar. et.al, 2012) might cause damages to genetic material (Deoxyribonucleic acid (DNA)) blocking their ability to divide further (Jackson.et.al, 2009). It might also destroy normal cells in the body and hence is a serious threat to a patient's health in long term is often not known.

Doctors play a crucial role for any type of therapy undertaken while dealing with various types of cancer patients. Wide variations are however observed across age groups and the related health conditions of patients. Information on different treatment techniques (including risks and costs) if available prior to the treatment, might help immensely the patient households and the clinics/ hospitals to take optimal decisions for cancer treatments. The government has provided different health schemes, especially for economically weak patients to support financially for the treatment of cancer (https://www. mohfw.gov.in). Several health schemes like Health Minister's Cancer Patient Fund, The Health Minister's Discretionary Grants, The Central Government Health Scheme, National Health Protection Scheme, The Prime Minister's National Relief Fund, Pradhan Mantri Jan Arogya Yojana (PM-JAY), State Illness Assistance Fund have been introduced nationwide for the financial support of cancer treatment, but in Assam, only two health schemes viz. Pradhan Mantri Jan Arogya Yojana (PM-JAY) and Atal Amrit Abhiyan (AAA) are available (https://www.mohfw.gov.in).

Thus, the present study is mainly focused on the effect of these two health schemes on treatment of lung cancer patients in Assam. The study is first of its kind for patients in Assam and has lot of policy implications in the sense that the common people through this would be able to take appropriate decision for cancer treatment based on socio-economic evaluations undertaken using the available information.

Review of Literatures: Cancer is an issue of major public health concern because not only it causes substantial suffering and shortens the natural lifespan of patients, but also have significant impact upon society as a whole (Chu et. al, 2008). Looking at the global scenario and studying the cancer incidence related spatial data, it has been observed that the incidence of lung cancer is a concerned sites of cancer as compared to others (Aggarwal et. al, 2016). Thus, several health schemes have been implemented for the treatment of cancer as the cost of treatment is at high (Angell.et.al, 2019). A study reveals that implementation of PMJAY scheme in India is hasty and also poses threats of diverting limited resources available for health in undesirable directions (Keshri.et.al, 2020).

Lahariya claims that to be effective and impactful in achieving the desired health outcomes, there is a need for getting both design and implementation of Ayushman Bharat Program right, from the very beginning (Lahariya C, 2018). In the same year, it was evaluated that success of public health insurance schemes do not depend only on government investments but also on wide spread awareness campaigns to educate the beneficiaries about the importance of such schemes (Agarwal.et.al, 2017). Another study concluded that by introducing PMJDY scheme, the government and RBI is able to bring a large number of people to formal financial channel and thereby helps in removing financial exclusion (Ravindra.et.al, 2020). Again, Yadawar, investigated that even if the base of the beneficiaries' increases, much more needs to be done to increase awareness about the PMJAY scheme to the public (Yadawar S,2020).

The research publications, cited above, indicated that no serious studies are taken up related to the the effect of national health schemes on treatment of lung cancer patients. Thus, this study of implementation of national health schemes on the treatment of lung cancer patients belong to Assam is taken up in order to fill the research gap.

Table 1. Categorization of the patients considered in the study on the basis of clinical and demographic parameters

\begin{tabular}{|l|c|c|c|}
\hline $\begin{array}{l}\text { Site of } \\
\text { Cancer }\end{array}$ & Parameters & Frequencies & Total \\
\hline \multirow{5}{*}{ Lung Cancer } & $\begin{array}{c}\text { Treated through } \\
\text { Schemes } \\
\text { (PMJAY/AAA) }\end{array}$ & & \\
\cline { 2 - 4 } & Yes & 163 & \\
\cline { 2 - 4 } & No & 37 & 200 \\
\cline { 2 - 4 } & Yes & 85 & 200 \\
\cline { 2 - 4 } & No & 115 & \\
\hline \multirow{5}{*}{} & Treatment status & & \\
\cline { 2 - 4 } & Complete & 176 & 200 \\
\cline { 2 - 4 } & Incomplete & 24 & \\
\hline
\end{tabular}

Objective of the study: The paper is designed keeping in view the following objective:

1. To study the impact of national health schemes on the treatment techniques of lung cancer patients.

\section{MATERIAL AND METHODS}

The data used for the present study is secondary in nature collected from the Cachar Cancer Hospital and 
Research Centre, Silchar, Assam, India for the year 2014-2019. Data were collected from a total of 200 lung cancer patients, who belonged to "Below Poverty Line" category as the health schemes are designed especially for economically weak patients to support financially for the treatment of cancer (https://www.mohfw.gov.in). Thus, the patients, who have the BPL card were considered as Below Poverty Line category in this study. The following table gives an overview of the dataset.

Now, Binary logistic regression model is applied to observe the probability of completion of treatment before and after implementation of these two health schemes with the other diseases take into consideration. Note that, the parameter "Other diseases" is considered because sometimes it may create the complication during the treatment and due the other disease, the treatment may be incomplete (Johnson.et.al, 2012).

In the present study, it will be convenient if we write our binary logistic regression model as follows:

$p=\frac{e^{\beta_{0}+\beta_{1} x_{1}+\beta_{2} x_{2}}}{1+e^{\beta_{0}+\beta_{1} x_{1}+\beta_{2} x_{2}}}$

where $p=$ Probability of completion of the treatment/ therapy

$\mathrm{x}_{1}=$ Treated through any of these two schemes (PMJAY/ AAA)

$\mathrm{x}_{1}=$ Other disease

Thus, we can write the model as follows:

$\log i t(p)=\beta_{0}+\beta_{1} \times$ Treated_through_any_of these_two_schemes $+\beta_{2} \times$ Other_Disease

Before including the parameters in the model, it is necessary to check the correlation between the independent variables as they can be misleading the overall result. Thus, the Correlation Matrices are computed to check whether independent variables are correlated to each other. Another important point is that some independent variables that can be included in the model may play a redundant role, which could directly effect on the model and thus cannot be considered as reliable. Thus, Variance Inflation Factor (VIF) test has been applied through multicolinearity analysis. The research question is that are both the schemes beneficial for the patients that are suffering lung cancer? Thus, if we find after the analysis that probability of completion of treatment is higher if the patients treated through these two schemes as compared to not using these schemes, then we may conclude that the patients are benefited from both the schemes.

\section{RESULTS}

At the outset, the correlation matrices are computed to check whether independent variable are correlated to each other before including them in the model. It is observed from Table 2 that the variables are not correlated to each other thus can be included in the model. Another important point is that some variables that can be included in the model may play a redundant role, which could directly effect on the model and thus cannot be considered as reliable. Thus, Variance Inflation Factor (VIF) test is also applied through Multicolinearity Analysis. We obtain from the Table 3 that there is no multicolinearity problem exist if we include the parameters in the binary logistic regression model as the VIF values are less than 5. Now, it is confirmed that there will be no misleading result by the inclusion of the parameters and thus obtain the following result.

Table 2. Correlation matrix for the parameters that are considered in the study

\begin{tabular}{|l|c|c|c|}
\hline \multicolumn{1}{|c|}{ Variables } & $\begin{array}{c}\text { Treated } \\
\text { through } \\
\text { any scheme }\end{array}$ & $\begin{array}{c}\text { Other } \\
\text { disease }\end{array}$ \\
\hline $\begin{array}{l}\text { Treated through } \\
\text { any scheme }\end{array}$ & $\begin{array}{c}\text { Pearson } \\
\text { Correlation }\end{array}$ & 1 & -0.008 \\
\hline & Sig. (2-tailed) & - & 0.909 \\
\hline Other disease & $\begin{array}{c}\text { Pearson } \\
\text { Correlation }\end{array}$ & -0.008 & 1 \\
\hline & Sig. (2-tailed) & 0.909 & - \\
\hline & N & 200 & 200 \\
\hline
\end{tabular}

We obtain from the Table 4 that chance of completion of treatment is 76.6 percent higher if the patients treated through the two schemes as compared to not using the schemes in case of lung cancer. On the other hand, chance of completion of treatment is 28.2 percent lesser if the patients have other disease as compared to have no disease in case of lung cancer. The results are significant as the $p$ value is less than 0.05 .

Table 3. VIF values for the parameters that are considered in the study

\begin{tabular}{|l|c|c|}
\hline Site of Cancer & Parameters & VIF values \\
\hline \multirow{2}{*}{ Lung Cancer } & $\begin{array}{c}\text { Treated through } \\
\text { Schemes }\end{array}$ & 1.000 \\
\cline { 2 - 3 } & Other disease & 1.000 \\
\hline
\end{tabular}

\section{DISCUSSION AND CONCLUSION}

Economic burden plays an important role in the growing incidence of cancer as the cost of treatment is expensive and the income losses are significant (Nair.et.al, 2014). It seems logical that economically weaker patients are not in the favour of early diagnosis of cancer due to the high cost of the treatments, thus results in poor chance of survival. Taking treatment at early stage of cancer can relief the pain as well prevent the cancer from 
metastasis (Sun.et.al, 2017). The patients are not often informed about the cause, nature and cost of therapies/ treatments. Since the treatment patterns of cancer and consequent impacts on the households are different, it is necessary to understand the major types of conventional treatments/procedures undertaken from time to time. This in turn is expected to provide information and choice to the patient families before undertaking any decision regarding treatment conditional upon availabilities and their abilities. The study has policy implications in the sense that it is expected to help optimal policy designs for the cancer patients in long run.

The present study is first of its kind for patients in Assam and focused on the effect of only two available health schemes viz. Pradhan Mantri Jan Arogya Yojana (PMJAY) and Atal Amrit Abhiyan (AAA) on treatment of lung cancer. The results show that both the schemes have successfully implemented on the lung cancer patients in Assam as the probability of completion of treatment is 76.6 percent higher if the patients treated through these two schemes as compared to not using these schemes. Previous study also concluded that by introducing
PMJDY scheme, the government and RBI is able to bring a large number of people to formal financial channel and thereby helps in removing financial exclusion (Ravindra. et.al, 2020).

But the particular study has revealed one surprising fact that even if the medical facilities/equipments in Assam have been improved, the percentage of completion of treatment is still poor if the patients have other disease as compared to have no disease in case of lung cancer. The chance of completion of treatment is only 28.2 percent, if the patients have other disease as compared to have no disease, which is a matter of serious concern and the study of this concerned posts as direction for further research. There may also be some other factors/ parameters involved that are having an impact on the chance of completion of treatment/therapy. Thus, study on those factors are left to be explored by researchers. In addition to this, the study has brought up the successful implementation of the national health schemes in Assam for the patients of lung cancer and expect to pave ways for further study on the other states of India as well as for different sites of cancer.

\begin{tabular}{|c|c|c|c|c|c|c|c|c|}
\hline \multirow[t]{2}{*}{ Parameters } & \multirow[t]{2}{*}{ B } & \multirow[t]{2}{*}{ S.E. } & \multirow[t]{2}{*}{ Wald } & \multirow[t]{2}{*}{ d.f. } & \multirow[t]{2}{*}{ Sig. } & \multirow[t]{2}{*}{ Exp.(B) } & \multicolumn{2}{|c|}{ 95\% C.I. } \\
\hline & & & & & & & Lower & Upper \\
\hline $\begin{array}{l}\text { Treat_through } \\
\text { Yes }\end{array}$ & & & & & & & & \\
\hline $\mathrm{No}^{\circledR}$ & .569 & .073 & .125 & 1 & .025 & 1.766 & 1.711 & 1.782 \\
\hline $\begin{array}{l}\text { Other_disease } \\
\text { Yes } \\
\mathrm{No}^{\circledR}\end{array}$ & -.331 & 495 & .445 & 1 & .004 & .718 & .710 & .720 \\
\hline Constant & -.438 & .348 & .176 & 1 & .000 & .645 & & \\
\hline
\end{tabular}

\section{REFERENCES}

Agarwal S, Y.J. (2017): The association between socioeconomic factors and breast cancer-specific survival varies by race. Plos One.

Aggarwal A, G.L. (2016): The State of Lung Cancer Research: A Global Analysis. J.Thoracic Onco.

Angell J.B, P.S. (2019): The Ayushman Bharat Pradhan Mantri Jan Arogya Yojana and the path to universal health coverage in India: Overcoming the challenges of stewardship and governance. Plos Med. 16(3)

Baghestani A, M.S. (2015): Survival analysis of patients with breast cancer using weibull parametric model. Asian Pac. J Cancer Prev. 8567-8571.

Baskar R, L.K. (2012): Cancer and Radiation Therapy: Current Advances and Future Directions. Internl J.Medic.Sci. 193-199.

Chu P, W.J. (2008): Estimation of life expectancy and the expected years of life lost in patients with major cancers: extrapolation of survival curves under high- censored rates. Value Health.

Fernandez L, L.J.(2014): Economic burden of cancer across the European Union: a population-based cost analysis. Lancet Oncol. 1165-1174.

Jackson S.P, B.J. (2009): The DNA-damage response in human biology and disease. Nature. 1071-1078.

Jemal A, S.R. (2010): Cancer Statistics 2010. Ca Cancer J. Clin. 277-300.

Keshri R.V, G.S. (2020): Ayushman Bharat and Road to Universal Health Coverage in India. J. Mahatma Gandhi Instit. Medical Sci. 24(2).

Lahariya C. (2018): Ayushman Bharat Program and Universal Health Coverage in India. Indian Pediatrics.

Nair S.K., R.S. (2014): Cost of Treatment for Cancer: Experiences of Patients in Public Hospitals in India. Asian Pac. J Cancer Prev. 5049-5054.

Rajpal S, K.A. (2018): Economic burden of cancer in India: Evidence from cross-sectional nationally representative household survey 2014. Plos one. 
Ravindra S.P, S.T. (2020): Does Pradhan Mantri Jan Dhan Yojana (PMJDY) scheme leads to better financial inclusion outcomes? An investigation. J. Critical Reviews. 2394-5125. 7(15).

Sun S.Y, Z.Z. (2017): Risk Factors and Preventions of
Breast Cancer. International J Biological Sci. 13871397.

Yadawar S. (2014): Ayushman Bharat Pradhan Mantri Jan Arogya Yojana: Performance so far and challenges ahead. Rgnul Student Research Review.6(138). 